\title{
PENGARUH KINERJA KEUANGAN TERHADAP NILAI PERUSAHAAN DENGAN CORPORATE SOCIAL RESPONSIBILITY DAN KEPEMILIKAN INSTITUSIONAL SEBAGAI VARIABEL PEMODERASI (STUDI EMPIRIS PADA PERUSAHAAN MANUFAKTUR DI BURSA EFEK INDONESIA)
}

\author{
Reni Yendrawati \\ Fakultas Ekonomi Universitas Islam Indonesia \\ reni@fe.uii.ac.id \\ Diwyacitta Pratidina \\ diwyacitta.pratidina@yahoo.co.id
}

Abstract
Researches on the influence of financial perfomance on corporate value have been widely conducted, however results inconsistency occured. Researches predicted that there are other influencing factors. This conditions drives researches to use CSR and GCG as moderating variables. This research aims to test the influence of financial performance on corporate value by considering the two moderating variables.

This research uses 25 manufacturing firms listed on the Indonesia Stock Exchange during 2009- 2011 as samples with 75 observation. Hypothesis is tested using moderated regression analysis to find out the interactive influence of the moderating variables. The corporate value measured using Tobin's $Q$, while disclosure of CSR and GCG are measured with the allocation cost of soical responsibility and institutional ownerships.

Result indicate that (1) EPS has a possitif effect on corporate value, (2) the allocation cost of social responsibility is able to moderate relation of EPS and corporate value, (3) but institutional ownerships are unable to moderate the relation of EPS and corporate value. This is possible because the institutional investor not only use EPS to make an investment decisions.

Keywords: financial performance, corporate value, corporate social responsibility, good corporate governance, institutional ownerships.

\section{PENDAHULUAN}

\section{Latar belakang}

Nilai perusahaan merupakan hal yang sangat penting. Dengan nilai perusahaan yang tinggi akan diikuti oleh tingginya kemakmuran pemegang saham. Semakin tinggi harga saham semakin tinggi pula nilai perusahaan yang menunjukan prospek perusahaan di masa yang akan datang. Banyak penelitian mengenai faktor-faktor yang mempengaruhi nilai perusahaan dilakukan.

Salah satunya adalah penelitian yang dilakukan oleh Sri Rahayu (2010) yang bertujuan untuk menguji kembali hubungan pengukuran kinerja dengan nilai perusahaan. Penelitian ini menggunakan ROE sebagai proksi dari variabel kinerja keuangan, 78 pengungkapan CSR sebagai proksi dari variabel CSR, dan kepemilikan manajerial sebagai proksi dari variabel GCG. Sample yang digunakan adalah 34 perusahaan manufaktur yang terdaftar di BEJ selama 
tahun 2007-2009. Hasil penelitian menunjukan bahwa ROE berpengaruh negatif pada nilai perusahaan, pengungkapan CSR dan kepemilikan manajerial terbukti berpengaruh terhadap hubungan antara ROE dan nilai perusahaan. Penelitian ini mereplikasi penelitian yang dilakukan oleh Sri Rahayu (2008), namun akan digunakan EPS sebagai proksi dari variabel kinerja keuangan, kepemilikan institusional sebagai proksi dari GCG.

Pentingnya CSR telah diatur dalam Undang-undang No. 25 tahun 2007 tentang Penanaman Modal dan Undang-undang No. 40 tahun 2007 tentang Perseroan Terbatas. Oleh karena itu, CSR merupakan suatu kewajiban bagi perusahaan, bukan sesuatu yang bersifat sukarela. Salah satu struktur kepemilikan dalam perusahaan adalah kepemilikan institusional. Menurut Faisal (2004) perusahaan dengan kepemilikan institusional yang besar mengindikasikan kemampuannya untuk memonitor manajemen. Semakin besar kepemilikan institusional maka semakin efisiensi pemanfaatan aktiva perusahaan dan diharapkan juga dapat bertindak sebagai pencegahan terhadap pemborosan yang dilakukan oleh manajemen. Tingginya kepemilikan oleh institusi akan meningkatkan pengawasan terhadap perusahaan. Pengawasan yang tinggi ini akan meminimalisasi tingkat penyelewengan-penyelewengan yang dilakukan oleh pihak manajemen yang akan menurunkan nilai perusahaan.

\section{Rumusan Masalah}

1. Apakah kinerja keuangan berpengaruh terhadap nilai perusahaan manufaktur di Bursa Efek Indonesia?

2. Apakah CSR akan dapat mempengaruhi mempengaruhi hubungan kinerja keuangan terhadap nilai perusahaan manufaktur yang terdaftar di Bursa Efek Indonesia?

3. Apakah Kepemilikan Institusional dapat mempengaruhi hubungan kinerja keuangan terhadap nilai perusahaan manufaktur yang terdaftar di Bursa Efek Indonesia?

\section{KAJIAN PUSTAKA}

Dalam jangka panjang tujuan perusahaan adalah memaksimumkan nilai perusahaan. Semakin tinggi nilai perusahaan menggambarkan semakin sejahtera pula pemiliknya. Nilai perusahaan akan tercermin dari harga pasar sahamnya. Menurut Suad Husnan dan Enny Pudjiastuti (2002) nilai perusahaan merupakan harga yang bersedia dibayar oleh calon pembeli apabila perusahaan tersebut dijual, semakin tinggi nilai perusahaan maka semakin besar kemakmuran yang akan diterima oleh pemilik perusahaan. Samuel $(2000)$ dalam Nurlela dan Islahudin (2008) menjelaskan bahwa enterprise value (EV) atau dikenal juga sebagai firm value (nilai perusahaan) merupakan indikator bagi pasar menilai perusahaan secara keseluruhan.

Kinerja adalah suatu gambaran mengenai tingkat pencapaian pelaksanaan suatu kegiatan perusahaan dalam mewujudkan sasaran, tujuan, misi dan visi organisasi yang tertuang dalam strategic planning suatu perusahaan. Sedangkan kinerja keuangan adalah prestasi kerja yang telah dicapai oleh perusahaan dalam suatu periode tertentu dan tertuang pada laporan keuangan perusahaan yang bersangkutan (Munawir, 1998).

Menurut Smith C (1994) yang dikutip dari Suta (2007), tanggung Jawab Sosial diperlukan agar perusahaan dapat meningkatkan reputasi perusahaan dan pada akhirnya juga akan meningkatkan kinerja perusahaan secara keseluruhan. CSR dalam penelitian ini diukur menggunakan konsep alokasi biaya tanggung jawab sosial yaitu suatu proses pemisahan suatu himpunan (set) atau jumlah nilai serta pembebanan subhimpunan (subsets) yang dihasilkan oleh perusahaan (laba) ke klasifikasi Tanggung Jawab Sosial sesuai dengan pendekatan struktural tradisional terhadap akuntansi. 
Kepemilikan institusional adalah kepemilikan saham perusahaan yang dimiliki oleh institusi atau lembaga seperti perusahaan asuransi, bank, perusahaan investasi dan kepemilikan industri lain (Tarjo, 2008). Kepemilikan institusional memiliki arti penting dalam memonitor manajemen karena dengan adanya kepemilikan oleh institusional akan mendorong peningkatan pengawasan yang lebih optimal. Monitoring tersebut tentunya akan menjamin kemakmuran untuk pemegang saham, pengaruh kepemilikan institusional sebagai agen pengawas ditekan melalui investasi mereka yang cukup besar dalam pasar modal.

\section{PENGEMBANGAN HIPOTESIS}

\section{Kinerja Keuangan dan Nilai Perusahaan}

Kinerja keuangan dalam penelitian ini diukur menggunakan EPS. Semakin tinggi EPS atau keuntungan per lembar saham yang didapatkan maka harga per lembar sahamnya akan semakin tinggi dengan asumsi jumlah saham yang beredar tetap. Bagi investor EPS yang tinggi berarti harapan untuk memperoleh keuntungan semakin besar. Hai ini disebabkan ketertarikan investor terhadap EPS yang tinggi akan mendorong permintaan atas saham tersebut meningkat sehingga harga sahamnya naik. Begitupun sebaliknya.

$\mathrm{H}_{1}$ : Kinerja keuangan berpengaruh positif terhadap nilai perusahaan.

\section{Kinerja Keuangan dan Nilai Perusahaan dimoderasi CSR}

Variabel kontingen CSR akan turut menginteraksi hubungan antara kinerja keuangan dan nilai perusahaan pada suatu kondisi tertentu. Desakan lingkungan perusahaan menuntut perusahaan agar menerapkan strategi untuk memaksimalkan nilai perusahaan. Strategi perusahaan seperti CSR dapat dilakukan untuk memberikan image perusahaan yang baik kepada pihak eksternal. Perusahaan dapat memaksimalkan modal pemegang saham, reputasi perusahaan, dan kelangsungan hidup jangka panjang perusahaan dengan menerapkan CSR. $\mathrm{H}_{2}$ : CSR mempengaruhi hubungan antara kinerja keuangan dengan nilai perusahaan.

\section{Kinerja keuangan dan Nilai Perusahaan dimoderasi KI}

Tata kelola perusahaan yang baik menggambarkan bagaimana usaha manajemen mengelola aset dan modalnya dengan baik agar menarik para investor. Jika perusahaan menerapkan sistem GCG, diharapkan kinerja perusahaan tersebut akan meningkat menjadi lebih baik, dengan meningkatnya kinerja perusahaan diharapkan juga dapat meningkatkan harga saham perusahaan sebagai indikator dari nilai perusahaan, sehingga nilai perusahaan meningkat. GCG diproksikan dengan KI.

$\mathrm{H}_{3}$ : $\mathrm{KI}$ mempengaruhi hubungan antara kinerja keuangan dengan nilai perusahaan.

\section{METODE PENELITIAN}

\section{Populasi dan Sampel}

Populasi yang digunakan dalam penelitian ini adalah perusahaan manufaktur yang terdaftar dalam BEI selama tahun 2009-2011. Metode pengambilan sampel adalah purposive sampling dengan kriteria: terdaftar dalam Bursa Efek Indonesia pada tahun 2009 - 2011, menerbitkan laporan tahunan berturut-turut selama tahun 2009-2011, tidak mengalami kerugian selama tahun $2009-2011$. 
UNISIA, Vol. XXXV No. 78 Januari 2013

\section{Variabel Penelitian dan Pengukuran}

1. Nilai Perusahaan

Nilai perusahaan diukur menggunakan Tobin's $Q$ :

$$
\mathrm{Q}=\frac{\left[\left(\mathrm{CP}^{\prime} \times \text { Junlah saluan }\right)+\mathrm{TL}+\mathrm{I}\right]-\mathrm{C} A}{\mathrm{~T} M}
$$

2. Kinerja Keuangan

Diukur menggunakan EPS:

$$
\text { Leps }=\frac{\text { laba borsih }}{\text { jumlah saham yang boredar }}
$$

3. Corporate Social Responsibility

Dihitung menggunakan:

$$
\text { Alokasi Biayo }=\frac{\text { Biaya Tanggung farab Sosial poda waktu }(t)}{\text { Laba (Rugi)bersih pada waktu }(t-1)} \times 100 \%
$$

4. Kepemilikan Institusional

Kepemilikan institusional diukur dengan perhitungan:

Kopamidikan lnstitusional $=\frac{5 \text { ham yang dimiliki institusional }}{\text { total jumlah sahtam yang boredar }}$

\section{Uji Model}

Model persamaan regresi yang akan diuji adalah sebagai berikut:

Tobin's $Q=a+b 1$ EPS + e

Tobin's $Q=a+b 1$ EPS $+b 2 C S R+b 3 E P S . C S R+e$

Tobin's $Q=a+b 1 E P S+b 2$ KI + b3IEPS-KII +e

Keterangan:

$$
\begin{array}{ll}
\text { Tobin's Q } & =\text { Nilai Perusahaan } \\
\text { a } & =\text { konstanta } \\
\text { b1, b2, b3 } & =\text { koefisien regresi } \\
\text { EPS } & =\text { variabel EPS } \\
\text { CSR } & =\text { variabel alokasi biaya dan tanggung jawab sosial } \\
\mathrm{KI} & =\text { variabel kepemilikan institusional } \\
\text { IEPS-KII } & =\text { moderasi selisih mutlak antara EPS dengan KI } \\
\text { e } & \text { = Error }
\end{array}
$$

Uji hipotesis menggunakan uji T dengan tingkat signifikan 0,05 , maka

1. Bila probabilitas < tingkat signifikansi $(\mathrm{Sig}<0,05)$, maka Ha diterima dan Ho ditolak, variabel independen berpengaruh terhadap variabel dependen.

2. Bila probabilitas $>$ tingkat signifikansi $(\mathrm{Sig}>0,05)$, maka Ha ditolak dan Ho diterima, variabel independen tidak berpengaruh terhadap variabel dependen. 
Pengaruh Kinerja Keuangan Terhadap Nilai Perusahaan ... Reni Yendrawati

\section{ANALISIS DAN PEMBAHASAN}

Pengaruh Kinerja Keuangan Perusahaan terhadap Nilai Perusahaan Dimoderasi oleh CSR

Pengujian ini dilakukan dengan analisis regresi moderasi. Hasil analisis moderasi antara kinerja keuangan terhadap nilai perusahaan dengan CSR sebagai variabel moderasi dapat ditunjukkan pada tabel berikut :

Tabel 1.

Hasil Regresi Moderasi Kinerja Keuangan terhadap Nilai perusahaan dengan CSR sebagai variabel moderasi

\begin{tabular}{|c|c|l|l|l|l|l|}
\hline Var. Independen & Koef. Regresi & $T$ & Sig & Adj. R Square & $F$ & Sig.F \\
\hline (Constant) & 0.961 & 7.701 & 0.000 & 0.269 & 10.085 & 0.000 \\
\hline EPS & 0.000070 & 2.677 & 0.009 & & & \\
\hline CSR & 1.523 & 1.486 & 0.142 & & & \\
\hline EPS*CSR & 0.000471 & 2.672 & 0.009 & & & \\
\hline \multicolumn{7}{|c|}{ Dependent Variabel: Tobin's Q } \\
\hline
\end{tabular}

Berdasarkan Tabel 1 dapat ditulis persamaan regresi moderasi adalah sebagai berikut: Tobin's $Q=0,961+0,000070$ EPS $+1,523$ CSR + 0,000471 EPS.CSR + e

\section{Pengaruh Kinerja Keuangan Perusahaan terhadap Nilai Perusahaan Dimoderasi oleh Kepemilikan Institusional}

Pengujian ini dilakukan dengan analisis regresi moderasi. Hasil analisis moderasi antara kinerja keuangan terhadap nilai perusahaan dengan kepemilikan institusional sebagai variabel moderasi dapat ditunjukkan pada tabel 2 :

Tabel 2.

Hasil Regresi Moderasi Kinerja Keuangan terhadap Nilai perusahaan dengan INST sebagai variabel moderasi

\begin{tabular}{|c|c|l|l|l|l|l|}
\hline Var. Independen & Koef. Regresi & $T$ & Sig & Adj. R Square & $F$ & Sig.F \\
\hline (Constant) & 1.068 & 2.212 & 0.030 & 0.161 & 5.725 & 0.001 \\
\hline$E P S$ & 0.000074 & 2.417 & 0.018 & & & \\
\hline$K I$ & -0.077 & -0.120 & 0.905 & & & \\
\hline$E P{ }^{*} K I$ & 0.000123 & 1.777 & 0.080 & & & \\
\hline \multicolumn{7}{|c|}{ Dependent Variabel : Tobin's Q } \\
\hline
\end{tabular}

Berdasarkan Tabel 2 dapat ditulis persamaan regresi moderasi adalah sebagai berikut:

Tobin's $Q=1,068+0,000074$ EPS - 0,077 Kl+ 0,000123EPS*KI+e 
UNISIA, Vol. XXXV No. 78 Januari 2013

Kesimpulan dari hasil pengolahan data ditunjukan dalam tabel berikut:

Tabel 4.11. Tabel Hasil Pengujian Hipotesis

\begin{tabular}{|c|l|c|}
\hline \multicolumn{2}{|c|}{ Hipotesis } & Hasil \\
\hline 1 & Kinerja keuangan berpengaruh positif terhadap nilai perusahaan & Didukung \\
\hline 2 & $\begin{array}{l}\text { Pengungkapan corporate social responsibilitymempengaruhi hubungan } \\
\text { antara kinerja keuangan dengan nilai perusahaan }\end{array}$ & Didukung \\
\hline 3 & $\begin{array}{l}\text { Kepemilikan Institusional mempengaruhi hubungan antara kinerja } \\
\text { keuangan dengan nilai perusahaan }\end{array}$ & $\begin{array}{l}\mathrm{T} \mathrm{i} \mathrm{d} \mathrm{a} \mathrm{k} \\
\text { Didukung }\end{array}$ \\
\hline
\end{tabular}

Pengaruh Kinerja Keuangan terhadap Nilai Perusahaan

Berdasarkan hasil regresi model 1 menemukan bahwa kinerja keuangan perusahaan yang diukur dengan EPS berpengaruh signifikan positif terhadap nilai perusahaan yang diukur dengan Tobin's Q. Kinerja keuangan perusahaan dalam penelitian ini diukur dengan Earning per share. EPS (Earning Per Share) atau pendapatan per lembar saham menunjukkan tingkat keuntungan yang diperoleh untuk setiap lembar saham biasa. EPS dapat diperoleh dengan membagi laba bersih perusahaan dengan jumlah saham beredar. Kemampuan perusahaan menghasilkan laba per lembar saham merupakan indikator fundamental keuangan perusahaan yang sering kali dipakai acuan untuk mengambil keputusan investasi dalam saham. Apabila EPS meningkat maka laba perusahaan semakin besar dan berdampak terhadap keuntungan yang akan diperoleh investor semakin besar. Dengan tingkat keuntungan yang semakin meningkat maka investor akan tertarik untuk membeli saham perusahaan. Namun, sebaliknya apabila EPS menurun maka laba yang akan diperoleh investor akan semakin kecil dan berdampak permintaan akan saham perusahaan turun sehingga akan menurunkan nilai perusahaan.

\section{Pengaruh Kinerja Keuangan terhadap Nilai Perusahaan dengan CSR sebagai Variabel Moderasi.}

Berdasarkan hasil regresi model 2 menemukan bahwa CSR terbukti memoderasi hubungan antara kinerja keuangan perusahaan yang diukur dengan EPS dengan nilai perusahaan yang diukur dengan Tobin's $Q$. Variabel kontingen corporate social responsibility akan turut menginteraksi hubungan antara kinerja keuangan dan nilai perusahaan pada suatu kondisi tertentu. Desakan lingkungan perusahaan menuntut perusahaan agar menerapkan strategi untuk memaksimalkan nilai perusahaan. Strategi perusahaan seperti corporate social responsibility dapat dilakukan untuk memberikan image perusahaan yang baik kepada pihak eksternal. Perusahaan dapat memaksimalkan modal pemegang saham, reputasi perusahaan, dan kelangsungan hidup jangka panjang perusahaan dengan menerapkan corporate social responsibility. Telah disebutkan dalam UU bahwa perusahaan yang aktivitasnya berhubungan dengan lingkungan alam wajib menerapkan corporate social responsibility. Perusahaan tidak hanya memandang laba sebagai satu-satunya tujuan dari perusahaan tetapi ada tujuan yang lainnya yaitu kepedulian perusahaan terhadap lingkungan, karena perusahaan mempunyai tanggung jawab yang lebih luas dibanding hanya mencari laba untuk pemegang saham.

\section{Pengaruh Kinerja Keuangan terhadap Nilai Perusahaan dengan Ki sebagai Variabel Moderasi.}

Berdasarkan hasil regresi model 3 menemukan bahwa GCG yang diukur dengan kepemilikan institusional tidak terbukti memoderasi hubungan antara kinerja keuangan 
perusahaan yang diukur dengan EPS dengan nilai perusahaan yang diukur dengan Tobin's Q. Hal ini disebabkan karena investor institusional merupakan investor yang sudah lama dan memiliki pengaruh yang cukup besar dalam investasi perusahaan. Motivasi investor ini tidak hanya keuntungan jangka pendek saja, tetapi lebih mengutamakan pada investasi jangka panjang. Investor institusional ini merupakan investor yang sudah berpengalaman, dan memiliki sistem perhitungan return dan risiko yang lebih profesional dibandingkan dengan investor individual, sehingga banyak faktor yang menjadi bahan pertimbangan dalam keputusan investasinya. Walaupun pada tahun berjalan EPS perusahaan mengalami penurunan bukan berarti menjadi pertimbangan utama bagi investor ini untuk menarik dananya. EPS yang turun bisa disebabkan karena tindakan konservatif manajemen dalam melaporkan laba, sehingga di tahun mendatang laba perusahaan akan meningkat lagi. Investor ini dalam menilai EPS tidak hanya dalam kejadian-kejadian tertentu, tetapi dianalisis melalui trend apakah EPS menunjukkan trend yang meningkat atau menurun, jadi bukan besarnya EPS tahun berjalan.

\section{PENUTUP}

\section{Kesimpulan}

Kesimpulan dari penelitian ini adalah kinerja keuangan berpengaruh terhadap nilai perusahaan, pengaruh kinerja keuangan terhadap nilai perusahaan dapat dimoderasi dengan CSR, namun pengaruh kinerja keuangan terhadap nilai perusahaan tidak dapat dimoderasi oleh Kepemilikan Institusional.

\section{Implikasi Penelitian}

1. Bagi perusahaan hendaknya meningkatkan CSR, karena dengan meningkatkan tingkat kepedulian sosial maka akan meningkatkan permintaan saham sehingga akan meningkatkan nilai perusahaan.

2. Bagi investor hendaknya memilih perusahaan yang mampu menghasilkan EPS lebih tinggi. Perusahaan dengan kinerja keuangan yang baik ini akan menguntungkan investor karena memiliki nilai perusahaan yang lebih baik.

\section{Keterbatasan Penelitian}

1. Jumlah sampel yang terbatas karena minimnya perusahaan manufaktur yang menerbitkan laporan keụangan dalam bentuk Annual Report.

2. Dalam pengukuran GCG dalam penelitian ini hanya terbatas pada kepemilikan institusional saja.

\section{Saran Penelitian Selanjutnya}

1. Untuk pengukuran GCG perusahaan menggunakan pengukuran lain misalnya komisaris independen, kualitas audit, dewan direksi, atau variabel lain.

2. Untuk pengukuran CSR perusahaan menggunakan pengukuran lain misalnya Sustainability. Reporting Guidelines.

3. Untuk pengukuran Kinerja Keuangan perusahaan menggunakan pengukuran lain misalnya ROE, ROA, RI, PER, atau NPM. 
UNISIA, Vol. XXXV No. 78 Januari 2013

\section{DAFTAR PUSTAKA}

Faizal. 2004. "Analisis Agency Costs, Struktur Kepemilikan dan Mekanisme Corporate Governance" Simposium Nasional Akuntansi VII. Denpasar Bali, 2-3 Desember.

Husnan, Suad dan Pudjiastuti, Enny, 2002, “Dasar-dasar Manajemen Keuangan”, AMP YKPN, Yogyakarta

Munawir, S., 2006, “Analisa Laporan Keuangan Edisi Keempat”, Yogyakarta: Liberty

Nurlela, Rika, dan Islahuddin, 2008, "Pengaruh Corporate Social Responsibility" Terhadap Nilai Perusahaan dengan Prosentase Kepemilikan Manajemen sebagai Variabel Moderating" SNA XI, Pontianak

Rahayu, Sri, 2010, "Pengaruh Kinerja Keuangan Terhadap Nilai Perusahaan dengan Pengungkapan Corporate Social Responsibility dan Good Corporate Governance sebagai Variabel Pemoderasi", Universitas Diponegoro, Semarang.

Suta, I Putu Gede Ary, 2007, "Kinerja Pasar Perusahaan Publik di Indonesia: Suatu Analisis Reputasi Perusahaan", Jakarta: Yayasan SAD Satria Bhakti

Tarjo, 2008, "Pengaruh Konsentrasi Kepemilikan Institusiona dan Leverage Terhadap Manajemen Laba, Nilai Pemegang saham serta Cost of Equity Capital", Simposium Nasioanal Akuntansi XI. Pontianak. 